\title{
Ciudad, televisión y fantasías: Vírgenes del Sol Inn Cabaret de Alexis Figueroa*
}

\section{City, Television and Fantasies: Alexis Figueroa's Vírgenes del Sol Inn Cabaret}

\author{
Magda Sepúlveda Eriz \\ Pontificia Universidad Católica de Chile, Facultad de Letras. \\ Santiago, Chile \\ msepulvu@uc.cl
}

.

Resumen • Vírgenes del Sol Inn Cabaret (1986), del poeta chileno Alexis Figueroa, recrea la complejidad de las relaciones en la cultura del tele-ver, en una sociedad tercermundista autoritaria y neoliberal. Con el cercenamiento del espacio público de la calle, la televisión ocupa su lugar e impone su única coherencia, esta es la rentabilidad comercial. Por ello, la ciudad bajo la influencia de la televisión es representada por Figueroa a través de la metáfora del cabaret, un territorio donde los movimientos principales son mostrarse y ver. De esta forma, las reflexiones del poemario giran en torno al comercio de las subjetividades y el consecuente aprendizaje del rol de actriz o público.

Palabras clave: Poesía chilena, Alexis Figueroa, ciudad, dictadura, televisión.

Abstract • The Chilean poet Alexis Figueroa's Vírgenes del Sol Inn Cabaret (1986) recreates the complexity of relationships in the tele-vision culture, in Latin American authoritarian and neoliberal society. With the curtailing of public space in the streets, the television usurps its place and imposes its one and only coherence: profit. This is why the city under the TV's influence is depicted by Figueroa using a cabaret as metaphor. A location where we find two main actions: showing off and watching. In this way, the reflections of the poem revolve around marketing subjectivities and subsequently learning from acting or watching.

Keywords: Chilean poetry, Alexis Figueroa, city, dictatorship, television.

Proyecto Fondecyt N 108.52.55: «La ciudad en la poesía chilena posgolpe», financiado por el Fondo Nacional de Ciencia y Tecnología, Fondecyt. Investigador responsable: Magda Sepúlveda. 
Alexis Figueroa (Concepción, 1954) obtuvo el Premio Casa de las Américas en 1986, con el libro Vírgenes del Sol Inn Cabaret (1986). ${ }^{2}$ A pesar de ello, el libro fue casi inadvertido por la crítica chilena. Las razones son muchas: era la época de la dictadura y un premio otorgado en Cuba era motivo de censura, los círculos del poeta estaban en la provincia, y no en la metrópoli, y la propuesta estética seguía líneas poco tradicionales. A pesar de que las primeras condiciones se han modificado, la situación del poemario no ha variado mucho, lo cual se debe a que el autor ha optado por trabajar solo, evitando pertenecer a grupos literarios. Alexis Figueroa no ha mantenido líneas de fuerza con sus compañeros de la llamada sgeneración del roneo`. ${ }^{3}$ Tal como él declara:

Con mi propia generación no guardo mucho contacto, y son muy pocos los que realmente me interesan. Eso sí, durante muchos años compartí — ubicados en la misma ciudad, Concepción- con Tomás Harris la búsqueda de la poesía (también) debo mencionar a Gonzalo Millán —aunque más antiguo diría-, entre los que me merecen respeto. Y a [José Ángel] Cuevas, el poeta del rock (Figueroa entrevistado por González).

A pesar de lo anterior, el poeta ha recibido importantes críticas. Marta Contreras, Sergio Vergara y Patricia Espinosa han abordado el poemario. Marta Contreras aprecia que Virgenes del Sol Inn Cabaret toma como protagonista la figura femenina, la cual «es recorrida en su superficie como un elemento movilizador de la atención y superpoblando un universo cuya ley es el placer» (1987: 5). Desde mi punto de vista, Contreras acierta al destacar el vínculo entre mujer y placer, ya que la voz enunciadora masculina mira con desapego la función de las mujeres como imágenes de exhibición. Sergio Vergara trabaja sobre la segunda edición del libro (Concepción: Papeles del Andalicán, 1986), que corresponde a un diseño de objeto, donde se integraron imágenes tipo collages, cuya característica es el marco donde se las inscribe, conformándose como retratos ovales, verdaderos espejos «circulares (cuya) redondez que, en un nivel, reproduce (el) deseo de ser cerrado como (los) televisores» (www.letras.s5.cl, 2008). Vergara destaca el cuestionamiento hacia la televisión, a través del cual el poemario estaría anunciando (advirtiendo) el efecto modelador de este aparato en los telescuchas y muy particularmente, de acuerdo al interés de Figueroa, en las audiencias femeninas. Patricia Espinosa observa que en el libro

\footnotetext{
El poeta penquista entró a estudiar filosofía en la Universidad de Concepción, carrera que no terminó, pero la permanencia en esta casa de estudios superiores le permitió integrarse al grupo que editaba la revista literaria Posdata (1982-1985), compuesto por los poetas Tomás Harris, Carlos Decap y Juan Zapata. Años más tarde participó junto a Jesús Sepúlveda, Jaime Lizama y Guillermo Valenzuela, en la creación de la revista Piel de leopardo (1992-1995). Entre otros textos que ha publicado se destaca el volumen de cuentos Hot Gatubela (Ed. Letra nueva, 1987) y el libro de poesía El laberinto circular y otros poemas (Ed. Documentos de la ventana oval, 1995).

2 A la fecha, la última edición del libro corresponde a Ediciones del Temple, 2007. La edición usada en el presente ensayo es la editada por Casa de las Américas.

3 La «generación del roneo〉 es llamada también «generación NN〉 en razón de que su actividad era silenciada, anónima, algunos escribían con seudónimos y su forma de publicación, generalmente producto de talleres, eran folletos mimeografados. Algunos integrantes que se atienen a esta descripción son: Erick Polhammer, Armando Rubio, Gregory Cohen, Antonio Gil, y Bárbara Délano, entre otros poetas habitantes de Santiago; en Concepción destacaban Tomás Harris, Ricardo Manque, Carlos Decap, Juan Zapata y Alexis Figueroa. Una caracterización acabada de estos grupos se encuentra en el texto de Tomás Harris, «Desarrollo de la poesía chilena 1960 - (1973) - 1990».
} 
las «mujeres parecen reproducir a la famosa Malinche; una suerte de eterno femenino, sobreexpuesto y violentado por la masculinidad de la cultura» (1964: 4). Me sumo a su análisis, destacando especialmente que la televisión se organiza sobre el rostro perfecto, la belleza absoluta, la gratificación sexual y la familia armoniosa, entre otras mitologías burguesas $^{4}$ que han hecho de las mujeres la fuente sostenedora. Y agrego a lo anterior que la tematización del fenómeno televisivo está revisada por Figueroa a través de una estética beat, pues en el poemario se recuperan ciertos artificios literarios de esta corriente norteamericana como la acumulación de elementos que imita el lugar de las mercancías en la sociedad postindustrial, ${ }^{5}$ el uso de anáforas en función de imitar los fraseos publicitarios de la televisión y la extensión del verso hasta volverlo ahogante. En Vírgenes del Sol Inn Cabaret, la acumulación y la saturación retóricas están desplegadas ahora como estrategias emuladoras del funcionamiento televisivo.

El texto de Figueroa registra un nuevo momento de la sociedad chilena, la cultura del tele-ver. ${ }^{6}$ La voz poética, un personaje masculino llamado en forma homónina al autor, está caracterizada justamente porque ve a distancia. Este personaje oficia como testigo que habla desde un ciberprostíbulo, un lugar lleno de pantallas de televisión, de cine y de espejos, que más que un espacio restringido, resulta ser una metáfora de la ciudad teledirigida. La voz poética presenta la situación de las actrices/cabareteras del lugar como metáfora de las mujeres latinoamericanas, mestizas, oprimidas por un régimen mirada. ${ }^{7}$ El ciberprostíbulo es apto no sólo para mostrar el efecto modélico de la pantalla, sino también para recrear la nueva dinámica de la ciudad neoliberal: alguien mira, un cliente, y alguien se exhibe, una prostituta. A la retórica beat de este hablante se suman imágenes surrealistas y artificios propios del lenguaje de la ciencia ficción, que sirven para hacer coincidir diferentes tiempos en el espacio del ciberprostíbulo. Estos tiempos corresponden a diversos momentos del régimen de la mirada.

Fredric Jameson, en su ensayo sobre la historia del régimen de la mirada, distingue tres fases en la reflexión efectuada a partir de la Segunda Guerra Mundial. El primer estadio,

\footnotetext{
Para Barthes, «la fotografía, el cine, el reportaje, el deporte, los espectáculos, la publicidad, todo puede servir de soporte para el habla mítica» (1970: 200). Y además considera que la formación de mitos es propia de la burguesía, pues «el mito tiene a su cargo fundamentar, como naturaleza, lo que es intención histórica, como eternidad, lo que es contingencia. Este mecanismo es, justamente, la forma de acción específica de la ideología burguesa» (Barthes, 1979: 237).

5 La sociedad posindustrial, ligada a los servicios y al consumo, comenzó en EE.UU después de la segunda Guerra Mundial, a fines de los 50. El ritmo beat en Ginsberg está relacionado con la lógica infinita de acumulación de mercancías de ese capitalismo, de ahí el verso infinito: «he used a triadic verse form he admired in the poetry of Williams Carlos Williams, extending the line out to the length of his own long breath» (Charters, 1992: 61).

6 La televisión se inició en 1959 en Chile, pero de forma muy elitista; su primera masificación ocurrió el año 1962, con ocasión de la transmisión del Mundial de Fútbol. Posteriormente, en 1978, se efectuó la primera emisión a color. Por tanto, el cambio de una cultura escrita o una cultura de la visualidad ocurrió fundamentalmente durante la dictadura (1973-1989).

7 El tema de la visualidad se inscribe dentro un conjunto de textos de la poesía chilena, publicada durante la dictadura, cuestión que se entiende dado el contexto de un «estado vigilante». Dentro de este corpus es posible integrar a La nueva novela (1977) de Juan Luis Martínez, que desarrolla el problema de la fotografía; algunos poemas de Purgatorio (1979) de Raúl Zurita, que se refieren a la imagen ante el espejo; Vía pública (1983) de Eugenia Brito, que posee una sección titulada «Fotografías»; e Introducción a Santiago (1982) de José Angel Cuevas, donde se discute el cambio de punto de mirada del observador en diversos momentos históricos, entre otros. Y en cuanto al vínculo con la visualidad del cine, lo relaciono con Diario de Navegación (1986) de Tomás Harris, con quien además comparte el modo retórico con que se trabaja la anáfora y el recurso al lenguaje colonial.
} 
consiste en la disquisición sobre los efectos de la mirada colonial que funcionó como un aparato de dominación cuya operación fue "convertir otra gente en cosas a través de la Mirada; este es el momento de la mirada colonial o colonizante, de la visibilidad como colonización» (Jameson, 1993: 13). El segundo momento, consiste en pensar la mirada desde los procesos de burocratización de ella, vale decir vincular la mirada con el castigo y por tanto con el poder. Jameson sitúa aquí el pensamiento de Foucault expresado en Vigilar y Castigar (1975). Y el tercero, la fase posmoderna, se caracteriza por discurrir sobre el predominio del espectáculo, vale decir, sobre un tipo de relación donde hay un espectador y un cuerpo/objeto exhibido. Quien opta por mostrarse, el exhibicionista, o las cabareteras en este caso, buscan desatar la pulsión escópica (deseo de ver) en el otro. El poemario de Figueroa, en su reflexión acerca de la mirada, se inscribe en el tercer momento, lo que no le impide cavilar sobre estadios anteriores.

El libro está dividido en cinco partes: «Vírgenes del Sol Inn Cabaret», «Miscelánea de María Madonna», «Miscelánea de Ester», «Miscelánea de Susana» y «Rumbo al epílogo", cada una de las cuales enfatiza un tipo de régimen escópico, pero sin eliminar los otros, produciendo esa mixtura temporal propia del texto posmoderno. En palabras de Vattimo, "la modernidad deja de existir cuando — por múltiples razones- desaparece la posibilidad de seguir hablando de la historia como una entidad unitaria [y ya] no se puede concebir la historia como realización progresiva» (1994: 10). De acuerdo a ello, Virgenes del Sol Inn Cabaret sería un texto posmoderno, que ya no cree en el progreso, sino que presenta a un sujeto preso en un conjunto de significantes icónicos los cuales no pueden ser reducidos a una unidad.

El primer tipo de régimen ocular, correspondiente a la mirada colonial, está expresado a través de un lenguaje que imita el «vosotros» antiguo y lo mezcla con la ciencia ficción, produciéndose esa mixtura temporal de la cual hablábamos en el párrafo anterior:

en estas regiones de una ciudad al sur del mundo

la necesidad de el vuestro — dollar money-, nos obliga a

comprenderos

pasad al buen comercio de postales,

dejar los trajes de mariners, de astronauta, en la percha

de la entrada

venid a este lugar que es la imprenta off-set de la libido

y sus sueños (Figueroa, 1986: 54).

El espectador está representado como un viajero, un «astronauta» o un «mariners» y el intercambio escópico remite a un tipo de soporte, la postal, que representó al sujeto indígena bajo la lógica de la pose. De acuerdo a la estudiosa en representaciones indígenas, Margarita Alvarado, el fotógrafo construyó una escena y una gestualidad. Un telón de fondo pintado reproducía «sutiles abedules europeos, arbustos complacientes y clásicas columnas, arco y jardineras de ornatos» (Alvarado, 2001: 19), lo que generaba una fotografía donde el indígena era un extraño en el escenario. La gestualidad solicitada a los indígenas correspondía a una visión sobre lo representado, anterior a la foto, y que en el caso de los varones mapuches exaltaba la posición bélica y, en las mujeres, la riqueza en metales como índice de una feminidad obligada. Las alhajas no les pertenecían, Margarita Alvarado ha demostrado que la mayoría de las joyas eran propiedad de los fotógrafos. Figueroa poetiza la mirada colonial como el momento del aprendizaje de verse alienado de sí mismo. Y plantea además que, al verse como otro, se crea el deseo de parecerse a lo representado en la imagen. 
La alienación que provoca la mirada colonial sobre los indígenas es entendida como una forma de exterminio en el poemario. Para Figueroa, la anulación de la etnicidad se produce por el deseo de imitar la representación ligada a las pinturas europeas, principalmente italianas renacentistas: «las muchachas se retocan afirmadas en el water, acodadas / en el lavamanos, / [...] /. Algunas juegan a ser modelos de Veermer, Rubens, / Boticelli» (20). En el poemario se plantea que el rechazo a la imagen propia es de larga data, lo que lo diferencia de Zurita quien desarrolla también en la idea del rechazo a la autoimagen, pero en un momento acotado, la vida de un sujeto concreto. Zurita insistirá sobre la escena del baño como el lugar donde se efectúa el rechazo a la propia imagen, la voz de Purgatorio dice: "Destrocé mi cara tremenda / frente al espejo / te amo - me dije - te amo// Te amo a más que nada en el mundo» (1993: 15). En Figueroa, el hablante enuncia también desde el baño: «Pero en todo caso, figueroa, / la cosa es que acá, adentro de este baño» (24). La importancia dada al baño tiene que ver con la higienización fascista que consideró a todo rebelde un sucio, un manchado. Por ello, el sujeto de Figueroa se define como manchado: "Y la mancha oscura —el sujeto de esta historia» (49). La alienación es entonces una constante histórica. Zurita trabajará con la mancha en el sujeto y en el paisaje: "Mira qué cosa: El Desierto de / Atacama son puras manchas / sabías? claro pero no te costaba nada mirarte un poco / también a ti mismo y decir / Anda yo también soy una buena mancha» (Zurita, 1993: 24). En ambos textos, el sujeto manchado elimina lo que considera su excrecencia en el baño y así se vuelve otro, se aliena.

Las mujeres del poemario buscan parecerse a lo representado en las imágenes y de esta forma transforman, mutilan y transan su cuerpo. Una vez degradadas ${ }^{8} \operatorname{trabajan~en~}$ un local nocturno de baja monta cuyo nombre es "Camino real», toponímico que alude a la ruta de encomenderos ${ }^{9}$ o mercaderes de cuerpos. El poemario entonces pliega dos tiempos del comercio de los cuerpos: el pasado colonial y el presente dictatorial. En el burdel lo ofrecido son las mujeres vírgenes del sol, pero ya no se trata de las impolutas incaicas, cuya misión era tejer para el Inca y mantener su castidad; sino que mujeres de un sol artificial, que ya no gozan del respeto y la vida retirada, sino que se inscriben en la ciudad como mercancías, prostitutas que se exterminan a sí mismas. La denominación de «Vírgenes del Sol» sirve entonces para mostrar el extravío de las mujeres indígenas acontecido a partir de reconocerse en un marco pictórico (las pinturas renacentistas) o fotográfico creado por extranjeros. ${ }^{10}$ Continuando la enajenación iniciada en la colonia, el espejo más contemporáneo, el cine, las ha empujado a modificar su imagen y asumirse como un objeto transable, «maqueta que se paga con la plata que evalúa / la piel toda dorada / el pelo color sol derramándose entre almohadas» (Figueroa, 1986: 54). El soporte del cine ha funcionado como espejo que las domestica y cuya marca de doblegamiento llevan en el cuerpo "cada huella de pisada, cada trazo está esbozado en el / vestido» (53). La alienación se marca también en el lenguaje verbal, en la mala ortografía a través de

El tema del menoscabo de las mujeres en la poesía de los 80 ha sido estudiado por Kemy Oyarzún en «Escritura de mujeres en Chile: Estéticas, políticas, agenciamientos».

- El Camino Real unía las ciudades de Concepción y Santiago en la época de la Colonia, circundando los poblados de Copequén y Mallohue, entre otros. La encomienda de Copequén fue asignada por Pedro de Valdivia a Pedro de Miranda en la primera repartición masiva que hizo a 70 vecinos y compañeros de armas en 1544. Esta y otras encomiendas implicaron la desestructuración de las relaciones económicas que existían antes de la Conquista.

10 Algunos de estos fotógrafos extranjeros analizados en el libro de Margarita Alvarado son Christian Valck, Gustavo Milet y Odber Heffer, entre otros. 
un «vien benidos a la máquina» (13). La «v», como diría Lacan, delata el inconsciente del que sabe que habla una lengua, el español, que no le pertenece. El error de ortografía nos indica que nunca hemos salido de ese tiempo donde fuimos mirados y representados. La falta de ortografía señala justamente nuestra falta.

Uno de los personajes del texto de Figueroa es Susana, ${ }^{11}$ quien está encandilada con las imágenes del cine, las cuales ella imita: "posando en el silencio a lo Caterine Deneuve / sonriendo en la butaca a lo Jacqueline Bisset, / a lo María Schneider sacudiendo su melena» (2007: 44). Esta imitación la vuelve a ella adúltera, en el sentido de una falsificación de sí misma. Desde este punto de vista, Figueroa presenta al cine como dispositivo de doblegamiento, pues "los cuerpos caminan por las calles sin oportunidad de / apagar el proyector» (46). La ciudad, por donde transitan estos cuerpos modelados por el cine, se transforma en el nuevo espacio del arte, en el nuevo salón de otoño. La urbe en su totalidad es un museo perverso que ha alterado el orden de lo imaginario, y donde todos somos «Vien benidos al salón de invierno luminoso» (46). ${ }^{12}$ La ciudad ilustrada definida por la luz del poder es saber, ha dado paso a la ciudad prostibularia regida por la luz que permite exhibir (se).

El espectáculo del cabaret se realiza en un espacio cerrado y vigilado: «los prados adyacentes pequeñas tanquetas los / recorren / robots incorruptibles son los guardias de las puertas; / existen haces de partículas secretos, camuflados en / los cercos; / diminutos misiles enterados en el pasto» (14). El ciberprostíbulo, tal como la ciudad, adquieren la apariencia de un campo de concentración. La visión de la mirada como un ojo vigilante, me permite plantear que en el poemario se da también una reflexión sobre el segundo tipo de régimen de mirada. En la ciudad cárcel creada por Figueroa se acepta la violencia y la humillación de los cuerpos: «Tampoco Sade ajeno es a nuestra casa: / un piso entero corresponde a sus dominios, / Georges Bataille administra una pieza manicomio repleta de videntes y ninfómanas. // Anton Artaud educa a las coristas, y Lautreamont pasea por el mundo, buscando nuevas / atracciones estelares» (13). Estos escritores conforman una isotopía donde se asocia la sexualidad con la destrucción. Otro autor citado es Pasolini, quien comparte con los anteriores el examen de la sociedad mediante la polémica con los vínculos sexuales, especialmente en Saló o los 120 días de Sodoma (1975), ${ }^{13}$ donde se plantea connotativamente que la noción de soberanía es fascista, pues se basa en encerrar los cuerpos y educar sus deseos. Figueroa trabaja en esa línea al afirmar que aquello deseado por la cultura dictatorial es la exhibición de un cuerpo domesticado al cual le está prohibido el goce íntimo, secreto y sólo puede optar al goce exhibido, el goce prostibulario. El dramaturgo Marco Antonio de la Parra simbolizó también esto en la obra La secreta obscenidad de cada día, donde un actor recorría el escenario mostrando su miembro viril tras abrir el impermeable. ${ }^{14}$ Una ciudad creada por Mussolini para los nazis.

La ciudad iluminada es un campo de concentración, donde las mujeres están identificadas: «Las mujeres llevan cinta roja, como si los viejos alemanes / hubieran llegado otra

\footnotetext{
" Susana al igual que el personaje homónino bíblico no sabe que es mirada. El personaje bíblico es vista desnuda por dos viejos que la acusan de adúltera cuando ella no accede a concederles favores sexuales. La mirada de los viejos vuelve adúltera a Susana. Sin embargo, finalmente, la honestidad de Susana se prueba, lo que le permite continuar casada.

12 El verso «Vien benidos al salón de invierno luminoso» conforma una isotopía en el texto que se configura como guiño al lector sobre el carácter de espectáculo que posee la nueva ciudad.

13 Saló (1943-1945) fue una ciudad creada por Mussolini para los nazis.

14 Obra de teatro estrenada en 1984. Una versión en video es la de Tatiana Gaviola, realizada en 1988.
} 
vez repartiendo brazaletes. / Sobre ellos léese 〈Susana〉, 〈María〉, 〈Ester»» (Figueroa, 1986: 19). A este lugar no llegan las luces naturales. La ciudad autoritaria se recluye, se torna hacia un interior donde no llega ni el sol ni la luna. Benjamin explica que el advenimiento de los faroles a gas en la ciudad moderna, significó que ya no fueron relevantes los poetas que le cantaban a las estrellas y a la noche natural; del mismo modo, en la ciudad dictatorial, los poetas se vuelcan a problematizar el foco de neón brillante y artificial. En Figueroa, tal como en La Divina Comedia de Dante, la entrada en los infiernos implica dejar atrás el sol natural, ${ }^{15}$ el poeta y otros sobrevivientes deambulan en lo oscuro, de una ciudad en ruinas y humeante: "nosotros avanzamos» (17) / "entre el humo» (21). La mayoría de los que habitan allí están muertos, son los que se han asesinado a sí mismos para poder participar del ciberprostíbulo. Los habitantes del cabaret parecen espectros: «muertos en los tonos falsos / del nuevo universo fluorescente, / muertos en la bóveda de plástico barato» (29). Quienes participan de la lógica fascista neoliberal no poseen vida: "Íbamos metiéndonos en el camino de la luz, dulce María, / estando desde el inicio todos muertos» (29). La situación de concebirse muertos encuentra su paradigma cultural en César Vallejo:

Estáis muertos.

Qué extraña manera de estarse muertos. Quienquiera diría no lo estáis. Pero, en verdad, estáis muertos, muertos.

[...]Estáis muertos, no habiendo antes vivido jamás. Quienquiera diría que, no siendo ahora, en otro tiempo fuisteis. Pero, en verdad, vosotros sois los cadáveres de una vida que nunca fue. Triste destino el no haber sido sino muertos siempre. El ser hoja seca sin haber sido verde jamás. Orfandad de orfandades (1979: 118).

Raúl Zurita en Purgatorio emplea también una intertextualidad con la Divina Comedia, ${ }^{16}$ y con el mismo sentido, aludir a lo infernal del espacio vigilado y al carácter espectral de los que allí habitan.

Figueroa junta la burocratización del ojo, propia del campo de concentración, con la masificación de la televisión, estableciendo así una sincronía entre el segundo y el tercer régimen escópico. El campo de concentración y la televisión comparten el «calcinar〉al ciudadano. Figueroa destaca los focos tipo cárcel que posee el escenario televisivo:

Welcome to the TV,

welcome to the machine.

Vien benidos al salon del invierno luminoso, (sic)

vien benidos al túnel del amor en las muchachas de las luces de neón.

Hoy tendremos cajas de cristal sobre la pista,

(Vien) benidos al lugar de las luces calcinantes, welcome to the machine (12).

El poema muestra el nuevo vínculo social generado por la televisión, se trata de un lazo doméstico que exige la presencia de un espectador. Las audiencias crean una comunidad de espectadores, donde cada uno sabe que el otro está también viendo. Figueroa

\footnotetext{
15 En La Divina Comedia encontramos esta referencia a lo oscuro: «me empujaba hacia allí donde el sol calla» (Dante Alighieri, 1999: 79).

16 En La Divina Comedia se dice: «A mitad del camino de la vida, / en una selva oscura me encontraba / porque mi ruta se había extraviado» (Dante 77). En «Purgatorio» se expresa: «Me encuentro en la mitad de mi vida. Perdí el camino» (Zurita 11).
} 
hace coincidir al espectador de la televisión con el espectador de la ciudad. Ambos saben que, tras lo visto, está la luz calcinante, metáfora amplia que abarca desde la iluminación del estudio televisivo hasta la aplicación de corriente como método de tortura. ${ }^{17}$ Figueroa asume una distancia crítica con estos espectadores que no toman conciencia de su participación en una máquina de la visión que los obliga a la pasividad.

Tal como en Lumpérica, la novela de Eltit publicada durante la dictadura militar de Augusto Pinochet, la luz juega un papel decisivo en la constitución del nuevo ciudadano. En el caso de Eltit, la mendiga es iluminada y recortada por un letrero publicitario de neón; en el caso de Figueroa los sujetos femeninos están siendo quemados por la luz del set de televisión o del set de tortura y además ellas producen la luz que han interiorizado. Los nuevos ciudadanos han recibido la luz del foco vigilante, del neón publicitario y de la televisión, pero mientras en Lumpérica la mendiga se retira de la influencia de la luz, en Figueroa desea estar cada vez más cerca de ella, aunque eso signifique ser quemada. Desde este ángulo, Figueroa presenta una visión más desencantada que Eltit, pues la electricidad es instrumento para el espectáculo y para la calcinación de loa cuerpos.

El personaje Ester, poetizado en Virgenes del Sol Inn Cabaret, sufre las consecuencias al tratar de seducir a un hombre inmovilizado por el tercer régimen escópico. Ella a diferencia de su antecesora bíblica ${ }^{18}$ no puede ejercer la seducción. Esto se debe a que la libido del varón es inexistente: "llega cansado por las noches de tanto trabajar / hoy Asuero prefiere jugar / flippers» (Figueroa, 1987: 35-6). El nuevo Asuero ha caído bajo otro régimen de visión que implica la distancia y no el establecimiento de la intersubjetividad presencial, él prefiere «mirarte en las revistas, comprarte en los videos» (36). Esta es la forma que asume el tercer tipo de régimen escópico, aquel donde el espectáculo a distancia se vuelve más interesante que la experiencia corporal, inmediata y real. Su manifestación más sutil es el voyeur ${ }^{19}$ incapaz de ejercer su sexualidad con la persona inmediata. El voyeur creado por Figueroa nos coloca frente al problema de la masculinidad en la ciudad dictatorial. Dado que el Estado se había construido sobre figuras masculinas, la derrota del proyecto político es simbolizada como pérdida de la virilidad; por ejemplo, en Zurita, la voz dice "Me llamo Raquel» (10) frente a una foto que representa el rostro de un hombre, a saber, Zurita. Este extravío de un ejercicio masculino se observa también en Figueroa, donde los personajes varones son sexualmente impotentes frente a un cuerpo, pero no frente a una imagen. El varón ha perdido la libido en relación con lo inmediato, por ello, la pareja se torna un imposible, en la intimidad, «ni ella ni él / [...] logran percibirse, menos verse» (38). La libido ha sido desplazada hacia los objetos de la vitrina, por ello, los que caminan por las calles no poseen vida emocional, son solo «animados golems de las ciudades» (39). La situación del personaje masculino del voyeur representada en la poesía escrita en dictadura es también elaborada en el poemario Escenas de peep

\footnotetext{
17 Uno de los métodos de tortura aplicados en Chile durante la dictadura era nombrado por sus víctimas como «la parrilla eléctrica» y consistía en provocar un dolor extremo mediante la aplicación de corriente eléctrica. El sufriente veía haces de luz en su mente.

18 La Ester bíblica deseaba atraer la mirada del buen soberano Asuero, pues veía en ello una forma para salvar al pueblo judío del exterminio con que amenazaba el primer ministro del rey. Ester logra ser mirada y que el primer ministro sea ahorcado, provocándose un nuevo contrato entre el pueblo y su gobernante.

19 La situación del mirón me recuerda la película La ventana indiscreta de Hitchcock, donde un hombre, confinado en una silla de ruedas, invierte su tiempo en observar a través de una ventana, sin apreciar a Grace Kelly que le declara su amor. Para el crítico sicoanalista Zizek, el error involuntario de Kelly es entorpecer la visión de la ventana, produciendo la molestia del mirón, quien sólo se interesa por ella cuando aparece al otro lado de la ventana, «dentro de lo observado» (2003: 164).
} 
show (1985) de Federico Schopf y está nuevamente relacionada con la incapacidad de ver lo ubicado en el presente inmediato, optándose por el fenómeno del distanciamiento. Grínor Rojo ha señalado la condición posmoderna de la voz en el poemario de Schopf, puesto que se trata de una subjetividad que «ha aprendido que lo único que existe es el público; que el público es el que nos hace ser lo que somos» (1987: 98). ${ }^{20} \mathrm{El}$ ciudadano masculino representado como un voyeur solo puede configurarse como público, tal como el televidente, y por lo tanto, no posee ni sexualidad efectiva ni heroísmo.

María Madonna, el último personaje, es una de las chicas del cabaret y en otra versión del poemario un grupo de muchachas cantantes de rock. ${ }^{21}$ María Madonna representa una imitación local pobre de lo aprendido en diferentes régimenes escópicos: las pinturas de la Virgen, las películas de Semana Santa y los videos de grupos musicales. ${ }^{22}$ Figueroa cita a Huidobro, pues este fue uno de los primeros que simbolizó, en Chile, los problemas de la tecnología en un país donde la modernidad no va a la par con procesos de democratización y secularización. La virgen de Figueroa y la huidobriana comparten el estar insertas en un ambiente tecnológico e iluminado. En Huidobro, la Virgen le dice al poeta: «mira mis manos: son transparentes como las bombillas eléctricas. / ¿Ves los filamentos de donde corre la sangre de mi luz intacta? [...] soy la capitana de las otras once mil que estaban en verdad demasiado restauradas» (1974: 22). Figueroa lleva esta imagen de la virgen como reproducción al mundo de los videos, con lo cual crea un personaje que representa la imitación pobre de una súper estrella, ella «lleva blusa transparente», "un collar de acrílico», "gafas punk», "guantes con uñas de cristal» (1987: 31). La distancia con Huidobro, se debe justamente a esta decadencia. Sin embargo, ambos comparten recalcar la condición provinciana de Chile, a María Madonna «antes de partir le regalaron un canasto» (32). María Madonna es la pérdida del sujeto, ella entera es un ícono. Figueroa introduce el problema de la homogeneidad de los cuerpos en consonancia temporal con la imposición de una máquina que solicitaba la falsificación, el simulacro: «welcome to the TV, welcome to the machine» (14). En la televisión, se continúa el crimen perfecto de los colonizados.

Las nuevas vírgenes del Sol, habitantes del ciberprostíbulo son productos fabricados según un modelo de identificación generado por un aparato técnico, fotografía, cine o televisión, que ha transformado la urbe en la «imprenta off-set de la libido y (los) sueños» (Figueroa, 1987: 54). El imaginario de la pantalla fractura, corta al sujeto, por eso los personajes femeninos poseen una estructura «mitad fuera mitad dentro (dentro)» (44). Una parte del sujeto está alienada, una parte está «(Casi en pantalla)» (45) y es aquella que le permite ejercer la ciudadanía como «seductriz» (30). Entonces, Figueroa plantea que la existencia del ciberprostíbulo se da en el contexto de la dictadura, donde el simulacro consistió en hacer creer que no había nada afuera, que todo era prostíbulo y que era obligación participar del juego.

El ciudadano construido por la dictadura militar implicó una tachadura sobre las identidades latinoamericanas, de hecho en Chile, ese tema desapareció hasta hoy del escenario

\footnotetext{
20 Grínor Rojo estudia el poemario en tanto texto del exilio, donde el referente aludido es New York, interpretación que comparto, no obstante pienso que el libro de Schopf posee también claves que tienen que ver con la situación dictatorial del país.

21 La versión donde María Madonna es el nombre de un grupo de rock es la editada en Concepción por Papeles del Andalicán, 1986.

22 En la edición de Papeles del Andalicán, Figueroa reforzó el vínculo de este personaje con los video-clips: «Yo soy esa que escucha The Police a todo trapo, / que se viste con The orgasmic Madonna Sound Machine» (25).
} 
cultural. El nuevo y limpio ciudadano expulsó de sí una parte de él, pero paradójicamente al realizar esta higienización se volvió abyecto. Por ello, Alexis Figueroa plantea que lo sucio es el ciudadano que habita en el burdel. La ciudad ramera está también en Berenguer quien en el poema "Santiago Tango" define a la metrópoli como «Carente de decencia, marginal, fantache / Pobre dama, empiela ramera» (17). Zurita en la extraña dedicatoria de Purgatorio alude a la prostitución como nueva forma de ciudadanía: «A Diamela Eltit, la santísima Trinidad y la pornografía» (14). Berenguer y Figueroa feminizan la ciudadanía deseada por el fascismo, bajo la idea de que el cuerpo cambiable y transable ha sido el de la mujer. Se nos educó para cumplir esa pequeña obscenidad de exhibirse cada día, pero sabemos que el precio a pagar, la falta de intimidad, es muy alto.

\section{REFERENCIAS}

Alighieri, Dante. (1999). Divina Comedia. Madrid: Cátedra.

Alvarado, Margarita. (2001). Mapuche. Fotografías siglo XIX y XX: Construcción de un imaginario. Santiago: Pehuén.

Barthes, Roland. (1970). Mitologías. Trad. Hector Schmucler. Madrid: Siglo XXI.

Benjamin, Walter. (1988). Poesía y capitalismo: Iluminaciones II. Trad. Jesús Aguirre. Madrid: Taurus.

Berenguer, Carmen. (1986). Huellas de siglo. Santiago: Edcs. Manieristas.

Charters, Ann. (1992). Beat Reader. New York: Penguin.

Contreras, Marta. (1987). El espacio poetizado en Vírgenes del Sol Inn Cabaret. Diario El Sur, 8, febrero: 5.

Eltit, Diamela. (1998). Lumpérica. 1983. Santiago: Seix Barral.

Espinosa, Patricia. (1996). La mirada de Alexis Figueroa. Suplemento Literatura y Libros. Diario La Época. Santiago, 3, noviembre: 4.

Figueroa, Alexis. (1986). Vírgenes del Sol Inn Cabaret. La Habana: Edcs. Casa de las Américas.

González, Yanko. (2008). Soy un accidente insectívoro. Entrevista a Alexis Figueroa. Obtenido el 5 de marzo de 2008 desde <http://www.letras.s5.com/af160504.htm>

Harris, Tomás. (2002). Desarrollo de la poesía chilena 1960 - (1973) - 1990. Mapocho 51, Santiago: Biblioteca Nacional: 41-73.

Huidobro, Vicente. (1974). Altazor. Valparaíso: Ediciones Universitarias.

Jameson, Fredric. (1993). Transformaciones de la imagen en la posmodernidad. Revista de critica cultural 6. Mayo: 12-25.

Kemy Oyarzún. (2003-2004). Escritura de mujeres en Chile: Estéticas, políticas, agenciamientos. Nomadias feministas 7. Santiago: Universidad de Chile: 7-20.

Vallejo, César. (1979). Trilce. 1922. Buenos Aires: Losada.

Vattimo, Gianni et al. (1994). En torno a la posmodernidad. Tad. Modesto Berciano Villalibre. Barcelona: Anthropos.

Vergara, Sergio. (2008). Vírgenes del Sol Inn Cabaret. Obtenido el 5 de marzo de 2008 desde <http://www.letras.s5.com/af370404.htm>

Rojo, Grínor. (1987). Exilio, modernidad y postmodernidad en tres poetas chilenos. Crítica del exilio: Ensayos sobre literatura latinoamericana actual. Santiago: Pehuén. PP. 79-106. 
Zizek, Slavoj. (1994). Goza tu sintoma: Jacques Lacan dentro y fuera de Hollywood. Trad. Horacio Pons. Buenos Aires: Nueva Visión, 1994.

(2003). El sublime objeto de la ideología. Trad. Isabel Vericat. Buenos Aires: Siglo XXI, 2003.

Zurita, Raúl. (1993). Purgatorio. $1^{\circ}$ edición, 1979. Santiago: Editorial Universitaria.

Recepción: abril de 2008

Aceptación: junio de 2008 